\title{
The Effects of Different Emoticons on the Perception of Emails in the Workplace
}

\author{
Claus-Peter H. Ernst \\ Frankfurt University of Applied Sciences \\ cernst@fb3.fra-uas.de
}

\author{
Martin Huschens \\ Johannes Gutenberg-Universität Mainz \\ huschens@uni-mainz.de
}

\begin{abstract}
Non-verbal communication cues, e.g. facial expressions, and their surrogates in computermediated communication, emoticons, influence how a message is understood. Based on the four-ear model of communication, we examine in detail how emoticons affect message perception. More specifically, we examine the different effects of three emoticons [:-) :-( ;-)] on the four levels that define communication. Using a factorial survey with a treatment control group design $(N=231)$, our findings suggest that emoticon usage does not influence the understanding of a message at the factual information and appeal levels. However, we show that the usage of happy and ironic emoticons significantly shapes the subtext of a message, namely the relationship and self-revelation level, whereas sad emoticons do not have such an effect. These findings hold practical implications: Most importantly, senders can use happy and ironic emoticons to soften their email messages' illocutionary force at the relationship level and self-revelation level.
\end{abstract}

\section{Introduction}

How a recipient perceives and understands a spoken message depends, on the one hand, on the verbal content, and, on the other hand, on the contextual interpretation of non-verbal elements such as facial expressions [30]. In the workplace context, computer-mediated communication (CMC), especially via email, has positioned itself as an alternative to faceto-face communication. However, in email communication, a sender has no direct opportunity to use non-verbal communication elements. Emoticons, however, as text-based symbolizations of facial expressions [26], can serve as corresponding cues.

The general effect of emoticons on the perception of messages has already been shown. Indeed, several studies have indicated that emoticons can be used as surrogates of non-verbal cues and are able to influence how a recipient understands a message [e.g., 6, 26].
The aim of our research paper is to shed light on the effects of emoticon usage in job-related email communication. More specifically, we examine how exactly different kinds of emoticons affect the understanding of different levels of messages in CMC in order to extend the current knowledge on the subject.

To this end, we based our study on the four-ear model of Schulz von Thun [25]. It postulates that every kind of communication has an underlying anatomy that is a combination of four different communication levels at which a message can be sent and received: the factual information level, the relationship level, the self-revelation level, and the appeal level. We hypothesize that happy, sad, and ironic emoticons exert different influences on all these communicationdefining levels in CMC.

To evaluate our hypotheses, we conducted a factorial survey [24] with 231 respondents and a treatment control group design in which we tested for the understanding of a message while one group was shown an email without an emoticon and three other groups were shown the same email but with one added emoticon each [:-) :-( ;-)]. Our findings suggest that both happy and ironic emoticons have a significant influence on the receiver's perception of messages at the relationship level and self-revelation level, but that they do not have an impact at the factual information level and appeal level. Moreover, sad emoticons seem not to have any influence on any communication level at all.

The paper is structured as follows: In the following section, we will introduce the four-ear model of Schulz von Thun [25] and its theoretical predecessor, the second axiom of Watzlawick et al. [30]. We will also provide the theoretical foundations of emoticon usage as text-based CMC cues. Following this, we will present our research model and research design. Finally, we will present and discuss our results before concluding our article with the limitations of our study and the implications of our results. 


\section{Theoretical Background}

\subsection{The Second Axiom of Watzlawick}

According to Watzlawick et al. [30], human communication is characterized by five axioms: (1) One cannot not communicate, (2) every communication has a content and relationship aspect such that the latter classifies the former and is therefore a meta-communication, (3) the nature of a relationship is dependent on the punctuation of the partners' communication procedures, (4) human communication involves both digital and analogic modalities, (5) every communication exchange is either symmetric or complementary, depending on whether it is based on equality or difference.

For our context, the second axiom provides important insights. It postulates that communication encompasses both a content aspect and a relationship aspect that mutually complement each other. While the content aspect refers to the factual information contained in the message, the relationship aspect indirectly provides information about the sender's point of view, in terms of how the recipient is to interpret the message.

In contrast to the content aspect, which is clearly expressed by logical digital language, i.e., words and sentences, the relationship aspect is primarily conveyed through analogue language. The analogue forms of communication contain facial expressions, gestures, and body language as well as prosodic features that are recognizable as variations within the framework of spoken language. More specifically, prosodic features present themselves through variations of tone strength and pitch, voice, melody, and rhythm. In this respect, analogue language provides information about the attitude of the sender to the conversation partner, the sender's opinion regarding the content of the message sent, and which expectations he or she has regarding the recipient's interpretation. In summary, the content aspect conveys pure data, while the relationship aspect specifies how this data should be interpreted [30].

\subsection{The Four-Ear Model of Schulz von Thun}

Schulz von Thun [25] expanded the idea of Watzlawick et al. [30] by further specifying the relationship aspect of communication. Indeed, Schulz von Thun [25] postulated that each message has an underlying anatomy that is a combination of four different communication levels at which a message can be sent and received, respectively: the factual information level, the relationship level, the selfrevelation level, and the appeal level. This model is also commonly termed the "four-ear" model, which refers to the ways in which the recipient understands (or hears) the message. The general process of communication and the four levels of a message are depicted in figure 1 .

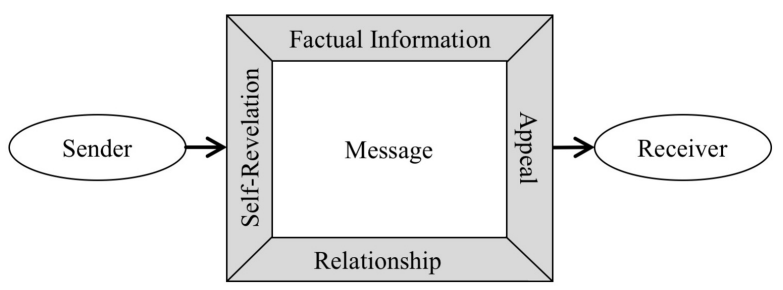

Figure 1. Communication process and four-ear model $[25$, p. 30$]$

At the factual information level, i.e., the content aspect of the message as defined by Watzlawick et al. [30], pure factual information is passed from the sender to the recipient. This communication layer is conveyed by the pure spoken word or the written text. At the factual information level, the recipient assesses whether a message is true or false, relevant or irrelevant, and reliable or unreliable.

Similarly to the corresponding argumentation of Watzlawick et al. [30], Schulz von Thun [25] argues that a message, besides the pure words used, inherently consists of an additional subtext or metamessage. This metamessage is only partly influenced by the pure textual information delivered by the sender. Rather, it is conveyed via non-verbal communication means, such as facial expressions, gestures, tone, speech speed and general body language, etc. However, whereas Watzlawick et al. [30] subsumes all metamessage aspects of communication under the term relationship aspect, Schulz von Thun [25] divided them into three different communication levels: the relationship level, the self-revelation level, and the appeal level.

At the relationship level, the sender indirectly expresses a position towards the recipient (so called we-messages). At the self-revelation level, the sender discloses information about himself/herself and their current motives, values, and emotions (so called Imessages). This level is described as a small sample of personality, since information about the communicator is inevitably revealed. This sample is, however, influenced by what the sender wishes to convey about himself/herself. Lastly, the appeal level provides information about the response expected of the recipient by the sender. This assertion suggests that the goal of messages is to produce an effect.

As an example, imagine a conversation between two colleagues where one tells the other "your report is not here". At the factual information level, the recipient may interpret the message as raw information regarding the current state of the process. At the 
relationship level, the recipient may understand the message as an accusation of incompetence of the sender towards himself/herself. At the appeal level, the recipient may feel an expectation to work more thoroughly in the future. At the self-revelation level, the recipient may get the impression that the sender was irritated by the delay.

\subsection{Emoticons as text-based computer- mediated communication cues}

Computer-mediated communication (CMC) is now established, and continues to steadily develop itself as a new form of communication. CMC can be defined as "[a]ny communicative transaction that takes place by way of a computer ..." [19, p. 552]. As a result, CMC can unite people via diverse channels and is particularly advantageous in that it bridges spatial and temporal barriers, thus simplifying and facilitating communication [13].

In contrast to real-life face-to-face communication, much of CMC today is founded on pure text such as emails and instant messages. In these contexts, analogue language normally used to clarify messages [30] is inaccessible. As a result, a sender's ability to show emotions, for example, is limited.

However, as a substitute for these missing elements, text-based elements have established themselves as non-verbal cues in written communication. These CMC cues can be equally effective as regular analogue language [28] and are thus able to help clarify messages [27] as well as provide information about the type and strength of the emotions that the sender wishes to convey with the message [11].

One popular form of CMC cues are emoticons, i.e., text-based symbolizations of facial expressions, emotional states, and feelings [26]. ${ }^{1}$ There is a wide choice of different emoticons ranging from the simple smiley face [:-)] to more sophisticated ones such as the shrugging person [\_(ツ)_「]

It has been shown that recipients of a message can largely identify the social and emotional meaning of an emoticon [16]. Indeed, emoticons are able to help to communicate a current mood or to provide information about the mental state of the sender $[5,15]$. Furthermore, using a positively connoted emoticon in the context of pure text can provoke a more positive

\footnotetext{
${ }^{1}$ In addition to text-based CMC cues, there are also pictographicbased cues such as emojis (e.g., :-), :-) ). However, they are currently primarily used in private communication such as in instant messaging services and in social media [cf. 18] and especially on touch-based mobile devices [22]. Since we are interested in jobrelated communication, we thus refrained from using emojis and focused on their text-based predecessors, i.e., emoticons [18].
}

attitude in the conversation partner [20]. Overall, as substitutes for real-life analogue language, emoticons give hints as to how factual information should be interpreted by conveying information over and above the pure content level of a message [30].

Since CMC is not only a means of social interaction in the private domain, but also popular within professional communication in the context of companies and organizations [21], emoticons are also used in job-related communications. Indeed, it has been shown that positive emoticons in the professional context provide three functions: (1) marking positive attitudes, (2) marking jokes/irony, (3) acting as hedges, i.e., strengthening expressive speech acts (such as thanks or greetings) or softening directives and criticism (i.e., requests, rejections, corrections, and complaints) [26].

Several studies have examined the effects of emoticons in CMC. Huang et al. [12] found that the use of emoticons in instant messaging has a positive effect on the enjoyment, personal interaction, perceived information richness, and perceived usefulness of an application. Whereas this study concentrated on private communication, Luor et al. [17] examined the effects of emoticon usage in taskoriented communication at the workplace. They concluded that emoticons strengthen positive or negative feelings especially in complex communications. In addition, according to their study, there is weak evidence that women use emoticons more frequently in the workplace, which was shown by Wolf [31] to also be in true in the private domain. Several other studies have proved that emoticons serve the function of clarifying textual messages by accentuating a tone or meaning $[6,15]$, thus, helping to communicate more clearly. However, to our knowledge, no study up till now has incorporated the four-ear model or specified the effects of emoticons on the different communication levels.

\section{Research Model}

While in face-to-face communication facial expressions can be used by the sender to provide information over and above the pure spoken words and to indicate how the recipient should interpret the message [30], in emails, emoticons can be used accordingly, since they are a form of text-based analogue language. In our study, we assume that emoticons exert comparable effects in CMC as facial expressions do in face-to-face communication - that is, they shape the subtext of a message. Thus, recipients will understand a message significantly differently if emoticons are used. 
More specifically, we expect to find a direct effect of our independent variable (assignment to one of the treatment groups or the control group) on all four levels of communication, namely the factual information level, the self-revelation level, the relationship level and the appeal level. Figure 2 presents our research model.

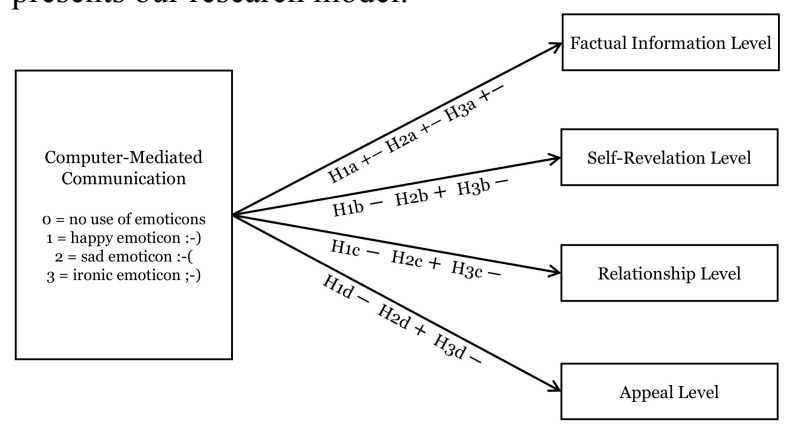

Figure 2. Research model

First, we believe that emoticons influence the understanding of a job-related email at the factual information level. More specifically, we believe this because each and every communicational cue, whether it is digital or analogue, influences the understanding of a message [25]: Just like facial expressions in faceto-face communication, an emoticon can amplify, weaken or even change the entire meaning of a message - especially if there is a discrepancy between the facial expression and the message content [cf. 30].

Similarly, we argue that emoticons significantly shape the metamessage of a message and, by that, also its perception. Just like facial expressions, emoticons provide enhanced information in terms of how a message should be understood. As Schulz von Thun [25] stated, the metamessage is conveyed to a large proportion by non-verbal cues such as facial expressions, gestures, and body language etc. Thus, we assume that emoticons that act as surrogates of facial expressions in $\mathrm{CMC}$ influence the levels of communication that carry the message's metamessage - namely the self-revelation, relationship and appeal levels. More specifically, we hypothesize that happy and ironic emoticons soften the illocutionary force of a message, whereas sad emoticons strengthen and emphasize the force of a message [6]. In summary, we hypothesize that:

The usage of a happy emoticon influences the recipient's perception of a message at the factual information level (H1a) and softens the illocutionary force of the message at the self-revelation level $(\mathbf{H} 1 \mathbf{b})$, the relationship level $(\boldsymbol{H 1 c})$, and the appeal level (H1d).

The usage of a sad emoticon influences the recipient's perception of a message at the factual information level (H2a) and strengthens the illocutionary force of the message at the self-revelation level $(\boldsymbol{H} \mathbf{2 b})$, the relationship level $(\boldsymbol{H} 2 \boldsymbol{c})$, and the appeal level $(\boldsymbol{H} \mathbf{2 d})$.

The usage of an ironic emoticon influences the recipient's perception of a message at the factual information level (H3a) and softens the illocutionary force of the message at the self-revelation level $(\mathbf{H} 3 \mathbf{b})$, the relationship level $(\boldsymbol{H} 3 \boldsymbol{c})$, and the appeal level (H3d).

\section{Research Design}

\subsection{Factorial Survey}

To test our hypotheses, we conducted a factorial survey. "Vignette studies [also called factorial surveys [24]] combine ideas from classical experiments and survey methodology" [2, p. 128]. More specifically, vignettes are "short, carefully constructed description[s] of a person, object, or situation, representing a systematic combination of [the investigation-relevant] characteristics" [2, p. 128]. Respondents are then confronted with these different fictional situation descriptions, and assess them on the basis of a questionnaire. Such situation descriptions may consist of a situational textual description, a video, illustrations or any other form of stimulation.

In our context, we asked our respondents to put themselves in the position of a company intern that receives an email from their supervisor, in which criticism is expressed (see table 2 for the introductory text): We used the vignette character of an intern because we expected to recruit a quite young sample of people - indeed, we posted the invitation to our survey online on two university news boards. We assumed that these subjects could quite easily put themselves in the position of an intern or might even have experienced such a situation themselves. Moreover, we used the scenario of receiving a criticism-expressing email, since criticism in the workplace is typically expressed with the goal of improving work performance [1] and senders commonly use "positive" analogue language to soften criticism and directives and to reduce the recipient's negative feelings. Similarly, "negative" analogue language is also of special importance when expressing criticism as it enables senders to strengthen and augment the words they accompany.

Since the defining factors of our research hypotheses are emoticons, we chose the presence and absence of emoticons as the factor levels of our vignettes. As a result, we had a total vignette population of four: four emails that were identical with regards to content and looks, but that differed with 
regards to the use of an emoticon. Indeed, one email contained a smiley-face emoticon [:-)], one contained a sad-face emoticon [:-(], one contained a winking-face emoticon [;-)], and one contained no emoticon at all, acting as a control (see table 2). The vignette itself was implemented as a mail client screenshot containing the message. We chose a visualized form of the vignette in order to increase the closeness to reality and to strengthen the priming effect.

Furthermore, we chose to implement a betweensubjects design [2] in which subjects were randomly assigned to the treatment and control groups and were only presented with one vignette. We believed that results from a within-subject design would have been severely flawed in our context, since subjects would not have been blind to condition (i.e., the different emoticons) and, thus, memory effects, sponsorship effects, and sequence effects would have come up.

Finally, in order to make sure that the vignette priming worked and that our respondents carefully read and understood the provided vignette situation, we asked them to answer three comprehension questions during the questionnaire (see table 2). If they answered one or more questions incorrectly, we asked them to reread the introductory text as well as the vignette before allowing them to proceed further.

In order to evaluate the influence of an emoticon on each of Schulz von Thun's communication levels, we developed three context-specific items for each layer for the subsequent questionnaire. All items were measured using a seven-point Likert-type scale ranging from "strongly disagree" to "strongly agree". Table 3 presents the items of our questionnaire.

\subsection{Data Collection}

We recruited German-speaking respondents by posting a call on the online news boards of two German universities. The participation was incentivized by a raffle of $50 €$ Amazon vouchers for three of the participants. In this manner, we obtained 231 online questionnaires. Table 4 presents the demographics and controls of our complete sample as well as of our four subgroups including sample size $(\mathrm{N})$, gender, age, highest educational achievement, and current profession.

As expected, our sample consisted mostly of students (87.4 percent), and, naturally, was quite young (mean: 19.70; std. dev.: .27). Furthermore, our sample consisted of more women (57.6 percent).
Table 2. Introductory text, comprehension test, and vignette situation

\begin{tabular}{|c|c|}
\hline $\begin{array}{l}\text { Introductory } \\
\text { text }\end{array}$ & $\begin{array}{l}\text { Please put yourself in the following position: } \\
\text { You are currently an intern in a company. Your } \\
\text { tasks include, among other things, the analysis } \\
\text { of business data. Yesterday, you sent a report } \\
\text { to your supervisor Michael Müller via email. } \\
\text { Now you receive the following answer of your } \\
\text { supervisor. Please share your impressions by } \\
\text { evaluating the following statements. }\end{array}$ \\
\hline $\begin{array}{l}\text { Control Group } \\
\text { Vignette } \\
\text { Critical email } \\
\text { without } \\
\text { emoticon }\end{array}$ & $\begin{array}{l}\text { Hello, } \\
\text { I noticed that the report you sent me yesterday } \\
\text { is incomplete and that the analysis is missing } \\
\text { some key figures. We have to sit down } \\
\text { together this afternoon*. } \\
\text { Best regards, } \\
\text { Michael Müller }\end{array}$ \\
\hline $\begin{array}{l}\text { Situation } \\
\text { Comprehension } \\
\text { Test }\end{array}$ & $\begin{array}{l}\text { What is your supervisor's name? [Andreas } \\
\text { Schmidt, Michael Meier, Michael Müller, } \\
\text { Marco Huber, Manfred Möller] } \\
\text { Concerning what has your supervisor contacted } \\
\text { you? [Concerning my unpunctuality, } \\
\text { concerning a flawed report, concerning an } \\
\text { impertinent attitude towards a colleague, } \\
\text { concerning a forgotten report, concerning an } \\
\text { incomplete report] } \\
\text { At what time does your supervisor want to } \\
\text { meet you? [Tomorrow morning, this afternoon, } \\
\text { this evening, tomorrow afternoon, today at } 4 \\
\text { p.m.] }\end{array}$ \\
\hline
\end{tabular}

\section{Results}

\subsection{Measurement Model}

To evaluate our measurement model, we performed a confirmatory factor analysis via SmartPLS 3.2.4 [23]. To test for significance, we used the integrated bootstrap routine with 5,000 samples [10].

Tables 5 and 6 present the correlations between constructs together with the Average-VarianceExtracted (AVE) and Composite-Reliability (CR), and our items' factor loadings, respectively: AVE and CR were at least .56 and .79, respectively, meeting the suggested construct reliability thresholds of .50/.70 [9]. All items but one $(\mathrm{FI} 2: \lambda=.64, \mathrm{p}<.001)$ loaded high (at least .76) and significant $(\mathrm{p}<.001)$ on their parent factor and, hence, met the suggested threshold of indicator reliability of $.70[10]$. 
Table 3. Items and descriptives

\begin{tabular}{|c|c|c|c|c|c|c|c|c|}
\hline \multirow{2}{*}{$\begin{array}{l}\text { Communication Level (C'Level) } \\
\text { Item (Label) }\end{array}$} & \multicolumn{2}{|c|}{ CG } & \multicolumn{2}{|c|}{$:-)$} & \multicolumn{2}{|c|}{$:-($} & \multicolumn{2}{|c|}{;-) } \\
\hline & Mean & SD & Mean & SD & Mean & SD & Mean & SD \\
\hline Factual information (FI) ${ }^{*}$ & $\overline{6.606}$ & .770 & 6.588 & .650 & 6.734 & .473 & $\overline{6.643}$ & .575 \\
\hline $\begin{array}{l}\text { My supervisor realized that my report for yesterday was } \\
\text { incomplete (FI1) }\end{array}$ & 6.636 & .778 & 6.609 & .789 & 6.796 & 626 & 6.655 & .637 \\
\hline $\begin{array}{l}\text { My supervisor noticed that the report I sent him yesterday } \\
\text { was not complete (FI2) }\end{array}$ & 6.564 & 1.084 & 6.531 & .991 & 6.685 & .886 & 6.620 & .895 \\
\hline $\begin{array}{l}\text { My supervisor observed that some key figures were missing } \\
\text { in the analysis that I sent him yesterday (FI3) }\end{array}$ & 6.618 & 1.063 & 6.625 & .745 & 6.722 & .656 & 6.655 & .807 \\
\hline Self-revelation $(\mathrm{SR})^{*}$ & 3.090 & 1.243 & 2.213 & .987 & 3.130 & 1.180 & 2.207 & $\mathbf{1 . 0 5 0}$ \\
\hline My supervisor is angry (SR1) & 3.000 & 1.333 & 1.890 & 1.056 & 2.981 & 1.366 & 1.896 & 1.119 \\
\hline My supervisor is upset (SR2) & 3.054 & 1.483 & 2.328 & 1.196 & 3.055 & 1.366 & 2.345 & 1.204 \\
\hline My supervisor is irritated (SR3) & 3.218 & 1.474 & 2.422 & 1.193 & 3.352 & 1.494 & 2.379 & 1.424 \\
\hline Relationship (R) $^{*}$ & 2.885 & 1.239 & 2.312 & 1.010 & 2.994 & 1.124 & 2.230 & 1.062 \\
\hline My supervisor thinks I am incompetent (R1) & 2.873 & 1.540 & 2.578 & 1.245 & 3.259 & 1.362 & 2.465 & 1.441 \\
\hline My supervisor thinks I am a lousy employee (R2) & 3.000 & 1.347 & 2.265 & 1.237 & 2.944 & 1.352 & 2.190 & 1.177 \\
\hline My supervisor does not like me (R3) & 2.782 & 1.357 & 2.093 & 1.231 & 2.778 & 1.298 & 2.034 & 1.14 \\
\hline Appeal (A) ${ }^{*}$ & 6.000 & .657 & 5.860 & .922 & 6.093 & .799 & 6.023 & .728 \\
\hline In the future, I will work more thoroughly (A1) & 6.000 & .839 & 5.906 & 1.123 & 6.204 & .7618 & 6.034 & .816 \\
\hline From now on, I will change my work habits (A2) & 5.501 & .920 & 5.406 & 1.065 & 5.667 & 1.303 & 5.534 & .959 \\
\hline I will try to deliver my reports complete hereafter (A3) & 6.491 & .767 & 6.266 & .877 & 6.407 & .942 & 6.500 & .778 \\
\hline
\end{tabular}

CG = Control group, :-) = Treatment group 1, :-( = Treatment group 2, ;-) = Treatment group 3 ,

CS = Complete sample, SD = standard deviation

* $=$ composite score per communication level, normalized with item count $(=3)$

Table 4. Demographics and controls

\begin{tabular}{|c|c|c|c|c|c|c|c|c|c|c|c|}
\hline Sample & CG & $:-)$ & $:-($ & ;-) & CS & Sample & CG & $:-)$ & $:-($ & ;-) & $\mathrm{CS}$ \\
\hline Sample size $(\mathrm{N})$ & 55 & 64 & 54 & 58 & 231 & & & & & & \\
\hline $\begin{array}{l}\text { Gender } \\
\text { Female } \\
\text { Male }\end{array}$ & $\begin{array}{l}29 \\
26\end{array}$ & $\begin{array}{l}39 \\
25\end{array}$ & $\begin{array}{l}33 \\
21\end{array}$ & $\begin{array}{l}32 \\
26\end{array}$ & $\begin{array}{c}133 \\
98\end{array}$ & \begin{tabular}{|l|} 
Age $(\mathbf{N}=\mathbf{2 2 8})$ \\
Mean \\
Std. Dev.
\end{tabular} & $\begin{array}{c}21.48 \\
.68\end{array}$ & $\begin{array}{c}19.42 \\
.49\end{array}$ & $\begin{array}{c}18.98 \\
.48\end{array}$ & $\begin{array}{c}19.00 \\
.47\end{array}$ & $\begin{array}{c}19.70 \\
.27\end{array}$ \\
\hline $\begin{array}{l}\text { Current profession } \\
\text { Pupil }\end{array}$ & 0 & 0 & 0 & 0 & 0 & $\begin{array}{l}\text { Highest education } \\
\text { Without certificate }\end{array}$ & 0 & 0 & 0 & 0 & 0 \\
\hline Student & 45 & 56 & 47 & 54 & 202 & High-school diploma & 22 & 27 & 29 & 33 & 111 \\
\hline Trainee & 0 & 1 & 1 & 0 & 2 & Vocational Baccalaureate diploma & 12 & 23 & 10 & 11 & 56 \\
\hline Employed & 6 & 6 & 4 & 3 & 19 & University degree & 20 & 13 & 12 & 12 & 57 \\
\hline Freelancer & 0 & 0 & 0 & 0 & 0 & $\mathrm{PhD}$ & 0 & 0 & 0 & 1 & 1 \\
\hline Pensioner & 0 & 0 & 0 & 0 & 0 & Other & 1 & 0 & 2 & 0 & 3 \\
\hline Job-seeking & 1 & 0 & 0 & 0 & 1 & No response & 0 & 1 & 1 & 1 & 3 \\
\hline Other & 2 & 1 & 0 & 1 & 4 & & & & & & \\
\hline No response & 1 & 0 & 2 & 0 & 3 & & & & & & \\
\hline
\end{tabular}

Nevertheless, we kept FI2 in our measurement model: "[I]ndicators with loadings between 0.40 and 0.70 should only be considered for removal from the scale if deleting this indicator leads to an increase in composite reliability above the suggested threshold value" $[10$, p. 145], which was not the case in our analysis, since all CRs already met their suggested threshold as indicated above. We thus kept all the indicators initially used. Finally, the loadings from our indicators were highest for each parent factor and the square roots of the AVE of all constructs were larger than the absolute value of the constructs' correlation with each other, thus indicating discriminant validity $[8,10]$.

\subsection{Descriptives}

Table 3 above also presents the descriptives per questionnaire item (mean and SD) and the average composite score for each communication level. We also examined the distribution properties of our sample. A first examination of the QQ-plots and a subsequent Shapiro-Wilk-test $\left(\mathrm{W}_{\mathrm{FI}}=.641, \mathrm{p}<.05\right.$; $\mathrm{W}_{\mathrm{SR}}=.941, \mathrm{p}<.05 ; \mathrm{W}_{\mathrm{R}}=.946, \mathrm{p}<.05 ; \mathrm{W}_{\mathrm{A}}=.908$, $\mathrm{p}<.05$ ) showed that our outcomes were not normally distributed. This also held true for the intra-group distribution which also deviated significantly from a normal distribution for each outcome variable. 
Table 5. Correlations between constructs [AVE (CR) on the diagonal]

\begin{tabular}{|l|c|c|c|c|}
\hline & FI & SR & R & A \\
\hline FI & $.56(.79)$ & & & \\
\hline SR & .01 & $.75(.90)$ & & \\
\hline R &. .04 & .78 & $.76(.90)$ & \\
\hline A & .43 & .09 & .01 & $.70(.88)$ \\
\hline
\end{tabular}

Table 6. Items' loadings (t-values)

\begin{tabular}{|l|c|c|c|c|}
\hline & FI & SR & R & A \\
\hline FI1 & $.83(16.2)$ & -.03 & -.08 & .40 \\
\hline FI2 & $.64(4.9)$ & .05 & .03 & .23 \\
\hline FI3 & $.76(9.0)$ & .04 & -.01 & .31 \\
\hline SR1 & .03 & $.91(59.0)$ & .68 & .11 \\
\hline SR2 & -.04 & $.83(25.0)$ & .59 & .04 \\
\hline SR3 & .03 & $.86(44.7)$ & .74 & .07 \\
\hline RE1 & -.06 & .68 & $.87(39.7)$ & .02 \\
\hline RE2 & .01 & .71 & $.89(48.1)$ & .03 \\
\hline RE3 & -.06 & .65 & $.85(36.0)$ & -.02 \\
\hline AP1 & .38 & .03 & -.06 & $.86(22.0)$ \\
\hline AP2 & .32 & .16 & .10 & $.80(17.7)$ \\
\hline AP3 & .39 & .03 & .01 & $.85(27.7)$ \\
\hline
\end{tabular}

\subsection{Hypothesis Testing}

We first applied an ANOVA to test for equality of all means [e.g., 7]. However, as the residuals were not normally distributed $\left(\mathrm{W}_{\mathrm{FI}}=.689, \mathrm{p}<.05 ; \mathrm{W}_{\mathrm{SR}}=.970\right.$, $\left.\mathrm{p}<.05 ; \mathrm{W}_{\mathrm{R}}=.967, \mathrm{p}<.05 ; \mathrm{W}_{\mathrm{A}}=.929, \mathrm{p}<.05\right)$, we had to switch to the non-parametric Kruskal-Wallis test to test for group differences [e.g., 7]. Table 7 presents the results.

Table 7. Results of Kruskal-Wallis tests

\begin{tabular}{|l|c|c|c|}
\hline C' Level $^{\prime}$ & H & df & p \\
\hline FI & 1.543 & 3 & $.672^{\text {n.s. }}$ \\
SR & 34.205 & 3 & $.000^{* * *}$ \\
R & 19.600 & 3 & $.000^{* * *}$ \\
A & 2.1262 & 3 & $.547^{\text {n.s. }}$ \\
${ }_{* * *}$ \\
indicates a significance level of .001.
\end{tabular}

The results of the Kruskal-Wallis test revealed that there were no significant group differences at the factual information level $\left(\mathrm{Mdn}_{\mathrm{CG}}=7.0, \mathrm{Mdn}_{\text {:- }}=7.0\right.$, $\left.\operatorname{Mdn}_{:-(}=7.0, \mathrm{Mdn}_{;-)}=7.0, \mathrm{H}(3)=1.543, \mathrm{p}=.672\right)$. Hence, hypotheses $H 1 a, H 2 a$ and $H 3 a$ had to be rejected: Message perception at the factual information level seems not to be affected by the usage of emoticons.

We also found no significant group differences at the appeal level $\left(\mathrm{Mdn}_{\mathrm{CG}}=6.0, \mathrm{Mdn}_{:-}=6.0, \mathrm{Mdn}_{:-(}=\right.$ $\left.6.0, \mathrm{Mdn}_{;-)}=6.0, \mathrm{H}(3)=1.543, \mathrm{p}=.547\right)$. Thus, H1d, $H 2 d$ and $H 3 d$ also had to be rejected: Emoticons seem not to shape how recipients perceive the expected response to a message. In our case, this means that, independently of the group assignment, all respondents understood that the supervisor wanted them to show better performance in the future.

In contrast, the Kruskal-Wallis test at the selfrevelation level revealed significant group differences $\left(\mathrm{Mdn}_{\mathrm{CG}}=3.0, \mathrm{Mdn}_{:-)}=2.0, \mathrm{Mdn}_{:-(}=3.0, \mathrm{Mdn}_{;-)}=2.0\right.$, $\mathrm{H}(3)=34.205, \mathrm{p}=.000)$. Post-hoc Dunn's tests were used to follow up on this finding and six pairwise comparisons were computed (see table 8 for the results). It appeared that perception of the message at the self-revelation level was not different when a sad emoticon was used compared to the control group

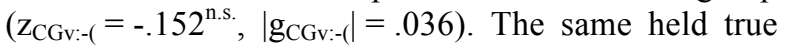
for the comparison of the happy and the ironic emoticon: Respondents showed no differences in perception at the self-revelation level $\left(\mathrm{z}_{\mathrm{i}-\mathrm{)} \text {; } ; \text {-) }}=.137^{\text {n.s. }}\right.$, $\left.\left|g_{:--) ;--)}\right|=.006\right)$. However, when we compared the control group with the treatment groups using a happy emoticon $\left(\mathrm{z}_{\mathrm{CGv}:-)}=4.047^{* *},\left|\mathrm{~g}_{\mathrm{CGv:-}}\right|=.788\right)$ or an ironic emoticon $\left(\mathrm{z}_{\mathrm{CGv} ;-)}=4.086^{* *},\left|\mathrm{~g}_{\mathrm{CGv;-}}\right|=.769\right)$, we found large treatment effects for both tests. The same held true when we compared the happy and ironic emoticon with the usage of the sad emoticon $\left(\mathrm{z}_{\mathrm{:}-\mathrm{)} \text { : } \mathrm{-}(\mathrm{f}}=-4.185^{* *}\right.$, $\left.\left|\mathrm{g}_{\text {:-)v:-( }}\right|=.847 ; \mathrm{z}_{\text {;-)v:-( }}=4.220^{* *},\left|\mathrm{~g}_{\text {;-)v:-( }}\right|=.828\right)$. Hence, $H 1 b$ and $H 3 b$ were confirmed, while $H 2 b$ had to be rejected: Happy and ironic emoticons seem to reduce the illocutionary force of a message significantly by shaping how a message is perceived at the selfrevelation level. In contrast, sad emoticons seem not to have such an effect.

\section{Table 8. Post-hoc pairwise comparisons, Dunn's test with Bonferroni correction and effect size}

\begin{tabular}{|l|c|c|c|c|}
\hline C' Level & Comparison & $\mathbf{z}$ & $\mathbf{p}$ & $\mid$ Hedge's g \\
\hline \multirow{4}{*}{ SR } & CG v :-) & 4.047 & $.000^{* *}$ & .788 \\
& CG v :-( & -.152 & $.440^{\text {n.s. }}$ & .036 \\
& CG v ;-) & 4.086 & $.000^{* *}$ & .769 \\
& $:-)$ v :-( & -4.185 & $.000^{* *}$ & .847 \\
& $:-)$ v ;-) & .137 & $.445^{\text {n.s. }}$ & .006 \\
& $;-)$ v :-( & 4.220 & $.000^{* *}$ & .828 \\
\hline \multirow{4}{*}{ R } & CG v :-) & 2.673 & $.004^{*}$ & .511 \\
& CG v :-( & -.595 & $.276^{\text {n.s. }}$ & .092 \\
& CG v ;-) & 2.931 & $.002^{* *}$ & .569 \\
& $:-)$ v :-( & -3.277 & $.000^{* *}$ & .640 \\
& $:-)$ v ;-) & .331 & $.370^{\text {n.s. }}$ & .079 \\
& $;-)$ v :-( & 3.519 & $.000^{* *}$ & .698 \\
\hline
\end{tabular}

The significance levels were corrected via

Bonferroni corrections: ** and * indicate significant $p$ values of $p<.0017$ and $p<.0083$, respectively. ${ }^{2}$

\footnotetext{
2 The Bonferroni correction controls for type I errors, which arise due to repeated pairwise comparisons, by dividing all significance levels by the number of pairwise comparisons (for example, the 5 percent significant level is corrected in our case to .0083 $(.05 / 6=.0083)[$ e.g., 7].
} 
Finally, the Kruskal-Wallis test also revealed group differences at the relationship level of the message $\left(\mathrm{Mdn}_{\mathrm{CG}}=3.0, \mathrm{Mdn}_{:-)}=2.0, \mathrm{Mdn}_{--)}=2.83, \mathrm{Mdn}_{:--}=2.0\right.$, $\mathrm{H}(3)=19.600, \mathrm{p}=.000)$. Again, six post-hoc Dunn's tests were performed for all pairwise comparisons. Results showed no effect of the sad emoticon on the relationship level when compared to the control group using no emoticon $\left(\mathrm{z}_{\text {CGv:- }-(}=-.595^{\text {n.s }}, \mid \mathrm{g}_{\text {CGv:- }-(\mid=.092)}\right)$. The same held true for the comparison of the happy

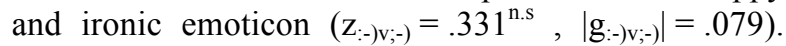
However, when we looked at the pairwise comparisons of the happy and ironic emoticon with the control group, we found significant group differences $\left(\mathrm{z}_{\mathrm{CGv}:-)}=\right.$ $\left.2.673^{*}, \mathrm{z}_{\mathrm{CGv} ;-)}=2.931^{* *}\right)$ and also large effect sizes $\left(\left|\mathrm{g}_{\mathrm{CGv:-}}\right|=.511,\left|\mathrm{~g}_{\mathrm{CGvi-}}\right|=.569\right)$ : Both the happy and ironic emoticons led to a different (more positive) perception of the message at the relationship level. In other words, the we-message conveyed in the email was perceived as more positively when a happy or ironic emoticon was used. This finding also held true when we compared the happy and ironic emoticon

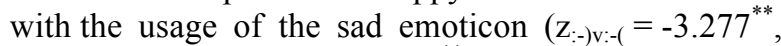
$\left.\left|\mathrm{g}_{\text {:-)v:-( }}\right|=.640 ; \mathrm{z}_{\text {;-)v:-( }}=3.519^{* *},\left|\mathrm{~g}_{\text {;-)v:-( }}\right|=.698\right)$. Thus, $H 1 c$ and $H 3 c$ were confirmed, while $H 2 c$ had to be rejected: Happy and ironic emoticons seem to lead to a more positive perception of a message at the relationship level, and sad emoticons seem not to have such an effect. In conclusion, we find that the use of happy and ironic emoticons causes recipients of a criticism-expressing email to perceive the sender's opinion of them as more positive than when no emoticon is used.

\section{Discussion}

Derks et al. [4] showed that emoticons are able to shape message interpretation; however, "[e]moticons do not have the strength to turn around the valence of the verbal message" [4, p. 386]. Our results support and refine these findings. Indeed, we found that happy and ironic emoticons have a significant influence on the metamessage of messages, namely on the selfrevelation level and the relationship level. However, at the factual information and appeal level, the influence of happy and ironic emoticons was insignificant. As a result, happy and ironic emoticons do not seem strong enough to dilute factual information and the response expected of the recipient by the sender, while at the same time they provide information at the selfrevelation and relationship levels, thus shaping recipients' interpretation of the I-messages and wemessages in job-related emails. In contrast, we found that a sad emoticon had no effect [:-(] on either of the four communication levels, which is in line with Walther and D'Addario [29], who were also unable to detect any effect of a negative emoticon on the interpretation of a negative message.

The insignificance of the effects of all three evaluated emoticons [:- $):-(;-)]$ on the factual information level supports the results of Derks et al. [4], who found that the verbal part of a message has more influence on message interpretation than the nonverbal part does. Indeed, recipients mostly use the content aspect of the message to evaluate the relevance, importance and trustworthiness of the information provided [25]. Emoticons are not strong enough to modify the message's verbal content.

One possible explanation for the insignificance of the effects of the evaluated emoticons on the appeal level interpretation is that emoticons are perhaps quite a weak cue whose effect is masked by the written words at this particular level. In other words, the response expected of the recipient by the sender is mainly conveyed by the text in text-based criticism.

A possible explanation for the additional insignificance of the sad emoticon at the self-revelation and relationship levels might be, in the specific case of criticism-expressing emails, that the perception of the written word itself is bad enough already. As a result, the sad emoticon might not be able to further strengthen that perception at the self-revelation and relationship levels. Similarly, following Watzlawick's first axiom (one cannot not communicate) the absence of an emoticon (which corresponds to no facial expression at all) might already lead to a strengthening effect that cannot be amplified by the use of a sad one.

In addition to the general effect of emoticons on the communication levels, we can also interpret the direction of the effects. In the specific case of an email expressing criticism, such as in our study, we see that happy and ironic emoticons can help soften the criticism while simultaneously retaining the factual information and appeal needed. In general, criticism can create negative associations at the relationship and self-revelation levels in the recipient. Indeed, people can take criticism personally [14], even though the criticism is typically expressed with the goal of improving work performance and is not meant personally [1]. Since a positive emoticon, such as the smiley-face and the winking-face, conveys a sender's positive attitude [20], its usage in an email expressing criticism reduces the negative associations of the recipient at the self-disclosure and relationship levels [25]. Finally, our results suggest that both smileys can be used interchangeably.

\section{Conclusions}

In this article, we evaluated the influence of different kinds of emoticons on recipients' 
interpretations of Schulz von Thun's four communication levels [25] in the context of workplace emails expressing criticism. Based on a factorial survey [24] with 231 respondents, our results suggest that happy and ironic emoticons exert an influence on two of the communication levels linked to the metamessage of a message, that is, the relationship level and the self-revelation level. More specifically, happy and ironic emoticons seem to be able to soften a messages' illocutionary force at the relationship level and self-revelation level. In contrast, we did not find a significant influence of these two kinds emoticons on the content level and the appeal level of the message. Furthermore, our findings suggest that sad emoticons do not exert an influence on any of the four communication levels.

These findings hold important implications. First, our study suggests that certain emoticons, but not all of them, can be a useful means for conveying information about the metamessage of a message, thus helping the recipient interpret the message in the intended way. Indeed, we showed that in the workplace context, happy and ironic emoticons can be used by senders in criticism-expressing emails in order to mitigate the recipients' negative associations with the messages at the relationship and self-revelation levels, while not diluting the factual information of the message or softening the illocutionary force at the appeal level. In other words, a recipient does take criticism less personally if the sender uses a happy or ironic emoticon and also has a more positive perception of the sender. At the same time, both emoticons do not inhibit the overall goal of criticism, i.e., the improvement of work performance. Furthermore, since we found no effects of sad emoticons on any communication level, supervisors should bear in mind that negative emoticons are not an effective way to influence the recipients understanding of a criticismexpressing message.

Our study has some limitations. Certainly, a situation that is described in a vignette can never be fully realistic and is especially prone to individual misperceptions. Thus, the external validity of our study might be limited, even though we tried to select an appropriate vignette situation that fit our targeted sample. Furthermore, there is a certain social distance between the supervisor and intern in our vignettes. In a future study, it would be interesting to examine the effects of different types of social distance between sender and recipient on message interpretation. More specifically, emoticons might have a different effect on message interpretation when used between individuals with low social distance, such as peers.

Additionally, we only used one specific vignette scenario. Although the scenario and the wording were carefully constructed, it is still possible that the respondents might have misinterpreted the emails. Indeed, the situation that was described in our fictitious scenario was not equally realistic for all respondents. For example, in the case of the employed subjects in our sample, it was maybe more difficult for them to place themselves in the role of an intern than it was for students. Nevertheless, our sample consisted mostly of German-speaking students (87.4 percent), mitigating that particular limitation.

At the same time, this sample composition brings other problems with regards to our study's external validity. Indeed, our results might not hold true for non-German speaking people and differences might also be found for other age groups.

Furthermore, there are certain limitations to between-subjects designs when it comes to perceptions, opinions and situational judgments as is the case in factorial surveys [3]. It can be argued that in between-subjects designs, each respondent judges only a single vignette, which can lead to measurement problems due to individually different vignette contexts. However, as described earlier, we think that the results from a within-subject design would be seriously flawed as subjects would not have been blind to condition and memory, sponsorship and sequence effects would have come up.

Moreover, we only included one specific incarnation of each kind of emoticon [:-) :-( ;-)] and put it only at one specific place in the email messages. Hence, there might be differences for other incarnations [e.g., :) :(;)] and also for different positions of the emoticon, for example, after the salutation.

As a next step, we want to broaden our study and take a look at different message contents and possible interaction effects. It seems reasonable that the effects of emoticons would significantly differ in different contexts. By building on the theoretical basis of the four-ear model, we thus also want to broaden the insights of Derks et al. [4], who already investigated the interaction effects of message content and emoticon effects.

Although our results hint to the fact that emoticons do not influence perception at the factual information level and appeal level, this result has to be replicated with other emoticons and different situations. Doing so in a controlled lab experiment could be a very promising approach for capturing the effects of emoticon usage in greater detail. Finally, in order to confirm our results, additional research must be conducted in other countries with participants of other age groups, while also including more vignettes with a greater number of emoticons and different message contents. 


\section{References}

[1] S. Ang, L. L. Cummings, D. W. Straub and P. C. Earley, "The Effects of Information Technology and the Perceived Mood of the Feedback Giver on Feedback Seeking", Information Systems Research 4 (3), 1993, pp. 240-261.

[2] C. Atzmüller and P. M. Steiner, "Experimental Vignette Studies in Survey Research", Methodology 6 (3), 2010, pp. 128-138.

[3] M. H. Birnbaum, "How to Show That $9>221$ : Collect Judgments in a between-Subjects Design", Psychological Methods 4 (3), 1999, pp. 243-249.

[4] D. Derks, A. E. R. Bos and J. von Grumbkow, "Emoticons and Online Message Interpretation", Social Science Computer Review 26 (3), 2008, pp. 379-388.

[5] D. Derks, A. H. Fischer and A. E. R. Bos, "The Role of Emotion in Computer-Mediated Communication: A Review", Computers in Human Behavior 24 (3), 2008, pp. 766-785.

[6] E. Dresner and S. C. Herring, "Functions of the Nonverbal in CMC: Emoticons and Illocutionary Force", Communication Theory 20 (4), 2010, pp. 249-268.

[7] A. Field, Discovering Statistics Using SPSS, Sage, Thousand Oaks, CA, 2009.

[8] C. Fornell and D. F. Larcker, "Evaluating Structural Equation Models with Unobservable Variables and Measurement Error", Journal of Marketing Research 18 (1), 1981, pp. 39-50.

[9] J. F. Hair, W. C. Black, B. J. Babin and R. E. Anderson, Multivariate Data Analysis, Prentice Hall, Upper Saddle River, NJ, 2009.

[10] J. F. Hair, C. M. Ringle and M. Sarstedt, "Pls-Sem: Indeed a Silver Bullet", Journal of Marketing Theory and Practice 19 (2), 2011, pp. 139-151.

[11] R. B. Harris and D. Paradice, "An Investigation of the Computer-Mediated Communication of Emotions", Journal of Applied Sciences Research 3 (12), 2007, pp. 20812090 .

[12] A. H. Huang, D. C. Yen and X. Zhang, "Exploring the Potential Effects of Emoticons", Information \& Management 45 (7), 2008, pp. 466-473.

[13] S. Kiesler and L. Sproull, "Group Decision Making and Communication Technology", Organizational Behavior and Human Decision Processes 52 (1), 1992, pp. 96-123.

[14] E. J. Kim, A. Yamaguchi, M.-S. Kim and A. Miyahara, "Effects of Taking Conflict Personally on Conflict
Management Styles across Cultures", Personality and Individual Differences 72 2015, pp. 143-149.

[15] F. B. Krohn, "A Generational Approach to Using Emoticons as Nonverbal Communication", Journal of Technical Writing and Communication 34 (4), 2004, pp. 321328.

[16] S. K. Lo, "The Nonverbal Communication Functions of Emoticons in Computer-Mediated Communication", CyberPsychology \& Behavior 11 (5), 2008, pp. 595-597.

[17] T. Luor, L. L. Wu, H. P. Lu and Y. H. Tao, "The Effect of Emoticons in Simplex and Complex Task-Oriented Communication: An Empirical Study of Instant Messaging", Computers in Human Behavior 26 (5), 2010, pp. 889-895.

[18] D. Marengo, F. Giannotta and M. Settanni, "Assessing Personality Using Emoji: An Exploratory Study", Personality and Individual Differences 112 2017, pp. 74-78.

[19] D. McQuail, Mcquail's Mass Communication Theory, Sage, London, UK, 2010.

[20] A. A. Mitchell, "The Effect of Verbal and Visual Components of Advertisements on Brand Attitudes and Attitude toward the Advertisement", Journal of Consumer Research 13 (1), 1986, pp. 12-24.

[21] P. O'Kane and O. Hargie, "Intentional and Unintentional Consequences of Substituting Face-to-Face Interaction with E-Mail: An Employee-Based Perspective", Interacting with Computers 19 (1), 2007, pp. 20-31.

[22] U. Pavalanathan and J. Eisenstein, "Emoticons Vs. Emojis on Twitter: A Causal Inference Approach", Proceedings of AAAI Spring Symposium on Observational Studies through Social Media and Other Human-Generated Content (OSSM).

[23] C. M. Ringle, S. Wende and J.-M. Becker, SmartPLS 3, http://www.smartpls.com, 2015

[24] P. H. Rossi and A. B. Anderson, The Factorial Survey Approach: An Introduction, in P. H. Rossi and S. L. Nock (eds.), Measuring Social Judgments: The Factorial Survey Approach, Sage, Beverly Hills, CA, 1982, pp. 15-67.

[25] F. Schulz von Thun, Miteinander Reden 1 Störungen Und Klärungen: Allgemeine Psychologie Der Kommunikation, rororo, Reinbek, DE, 2001.

[26] K. Skovholt, A. Grønning and A. Kankaanranta, "The Communicative Functions of Emoticons in Workplace E-Mails: :-)", Journal of Computer-Mediated Communication 19 (4), 2014, pp. 780-797.

[27] I. Vandergriff, "Emotive Communication Online: A Contextual Analysis of Computer-Mediated Communication (CMC) Cues", Journal of Pragmatics 51 2013, pp. 1-12. 
[28] J. B. Walther, Theories of Computermediated Communication and Interpersonal Relations, in M. L. Knapp and J. A. Daly (eds.), The Handbook of Interpersonal Communication, Sage, Thousand Oaks, CA, 2011, pp. 443479.

[29] J. B. Walther and K. P. D'Addario, "The Impacts of Emoticons on Message Interpretation in Computer-Mediated Communication", Social Science Computer Review 19 (3), 2001, pp. 324-347.
[30] P. Watzlawick, J. B. Bavelas and D. D. Jackson, Pragmatics of Human Communication. A Study of Interactional Patterns, Pathologies, and Paradoxes, W. W. Norton \& Company, New York, NY, 2011.

[31] A. Wolf, "Emotional Expression Online: Gender Differences in Emoticon Use", CyberPsychology \& Behavior 3 (5), 2000, pp. 827-833. 